English, M. P. (1954). J. gen. Microbiol. 10, 328-336

\title{
Some Observations on the Physiology of Saccharomyces rouxii Boutroux
}

\author{
BY MARY P. ENGLISH \\ Bacteriological Laboratory, Physiological Department, The British Drug Houses Ltd., \\ Graham Street, London N. 1
}

SUMMARY : Saccharomyces rouxii is shown to be tolerant of a wide range of acidities and of sugar and salt concentrations, but sensitive to temperatures above $35^{\circ}$ unless protected by a small quantity of sugar in the medium.

A limited investigation into the vitamin nutrition and nitrogen requirements of the yeast is reported.

The work described in this paper forms part of an investigation into the fermentation of malt extract by the osmophilic yeast Saccharomyces rouxii Boutroux (English, 1953), and was undertaken in order to throw further light on factors affecting that fermentation.

Little physiological work has been carried out with this yeast, either under its present name, or that under which it was originally identified for me by Dr Kreger van Rij (English, 1953) Zygosaccharomyces japonicus Saito, though Fabian \& Quinet (1928) and Fabian \& Hall (1933) found its thermal deathpoints in various substrates to the nearest $5^{\circ}$.

Among other osmophilic yeasts, an extensive investigation into the metabolism of $\boldsymbol{Z}$. acidifaciens has been carried out by Nickerson \& Carroll (1945), but they were mainly interested in factors affecting its respiration, and in the products of the fermentation. Nickerson \& Thimann (1943) studied some aspects of the vitamin requirements of the same yeast. Kroemer \& Krumbholz (1931, 1932) and Krumbholz (1931 $a, b)$ have made detailed studies of the effect of temperature and concentration of substrate on various osmophilic yeasts from wine must.

\section{MATERIALS AND METHODS}

The isolate $\mathbf{G} 1$ of the malt extract strain of $S$. rouxii, described previously (English 1953), was used for all experiments, though in some cases other isolates were used in addition, and gave exactly similar results. Stock cultures were maintained as before, and the same basal medium was used, to which enough glucose was added to give the required osmophilic conditions. Glucose was chosen for these experiments in preference to maltose (the predominant sugar in malt extract) because, being a monosaccharide, there is no danger of further hydrolysis and because the osmotic pressure of a given solution is greater than that of a maltose solution of equal concentration. The solubility of L-glucose in water at $25^{\circ}$ is about $45 \%(\mathrm{w} / \mathrm{w})$ : solutions as concentrated as $69 \%(w / w)$ ean, however, be obtained by slight initial warming of the syrup, as mutarotation of some of the L-glucose to the more soluble $\beta$-glucose occurs (Jackson \& Silsbee, 1922). Though in a metastable condition, these solutions 
were found to be quite satisfactory in practice, crystallization occurring seldom, and then only in the $69 \%$ solution.

For work on the $\mathrm{pH}$ range of the yeast, the $\mathrm{pH}$ of the sterile medium was adjusted aseptically, in bulk, and the medium was then tubed aseptically. Any two consecutive compounds of the following four- $-\mathrm{H}_{3} \mathrm{PO}_{4}(1 \cdot 0 \mathrm{~N})$; $\mathrm{KH}_{2} \mathrm{PO}_{4}(1.0 \mathrm{M}) ; \mathrm{K}_{2} \mathrm{HPO}_{4}(1.0 \mathrm{M})$; and $\mathrm{NaOH}(1.0 \mathrm{~N})$-were used as buffers, to a total of $10 \mathrm{ml}$. in $250 \mathrm{ml}$. medium. As it had previously been observed that the $\mathrm{pH}$ of the uninoculated media drifted somewhat during storage at $30^{\circ}$, all adjusted media were stored at this temperature for $\mathbf{3}$ days before use, by which time a steady value was reached.

To obtain spores for thermal death-point determinations the yeast was at first grown on slopes made from commercial plaster of Paris, moistened with distilled water, but the percentage viability of spores obtained under these conditions was low. Subsequently it was found that spores with a high percentage viability were formed very freely on 2-week old malt agar slopes, and these spores were used for the determinations.

All treatments were carried out in duplicate, and experiments were repeated at least once. Points on graphs represent average results for one experiment. Incubation was at $30^{\circ}$ unless otherwise stated.

Growth of the yeast in liquid cultures was measured on a Hilger and Watts 'Spekker' absorptiometer, results being recorded as readings from the drum of the instrument without attempting to estimate the number of cells actually present. Owing to the increasing transparency of yeast cells in media of increasing concentration, comparison of growth of the yeast at different sugar concentrations by this method is not valid. Differences in behaviour at the same concentration, brought about by varying other enviromental conditions, may, however, be compared.

Serial readings of $\mathrm{pH}$ were made colorimetrically with B.D.H. capillator tubes, a convenient method where only very small samples are available and great accuracy is not essential.

Thermal death-points were determined by the capillary tube method.

\section{RESULTS}

\section{Adaptability to media of different concentrations}

Saito (1907), in his original isolation of Z. japonicus from 'koji', used a $17 \%$ solution of sodium chloride, with suitable nutrients, as a selective medium; hence it is of interest to compare the reaction of the malt extract isolate in this and other concentrated media. The yeast was therefore grown in the basal medium to which different concentrations of salts and sugars were added, with the results shown below.

Glucose. Fermentation of a $69 \%(\mathrm{w} / \mathrm{w})$ solution is apparent in 5 days, the cells appearing normal in size and shape.

Maltose solution containing $90 \mathrm{~g}$. sugar in $100 \mathrm{ml}$. water shows visible fermentation in $\mathbf{5}$ days.

$\mathrm{KNO}_{3}$. Very sparse growth occurs in a saturated solution. 
$\mathrm{NaCl}$. The yeast can grow sparsely in a $17 \%(\mathrm{w} / \mathrm{v})$ solution, but the cells are malformed and grow in clumped colonies, apparently due to the failure of buds to separate completely from the parent cells.

Saito does not mention malformed cells in his cultures in $17 \%$ salt solution, so it seems probable that the malt extract strain of the organism differs from the 'koji' strain in this respect. The rapid and luxuriant growth of the yeast in the basal medium alone, shows that it is a facultative rather than an obligate osmophile. This is also borne out by the observation that after prolonged cultivation on basal medium alone, the yeast loses its power to ferment $69 \%$ glucose solutions, but can be 'retrained' by successive transfers through media of increasing sugar content, a phenomenon also reported for osmophilic yeasts by Ingram (1950) and Scarr (1951).

The adaptive capacity of $S$. rouxii when transferred quickly from highly concentrated media to very dilute ones, and vice versa, is remarkable. Cultures grown in $61 \%(\mathrm{w} / \mathrm{w})$ glucose solution can be transferred to distilled water (with immersion in one intermediate dilution lasting about $15 \mathrm{~min}$. necessary to reduce the density of the medium sufficiently to allow sedimentation of the cells on centrifuging) with apparently no effect on their viability; even after soaking in water for $24 \mathrm{hr}$, viability is only slightly decreased. The same holds true when cultures grown in the basal medium are transferred to $61 \%$ glucose solution. Microscopic observations revealed no obvious damage to the cells.

\section{Effect of temperature and concentration of the medium}

In this experiment the yeast was grown in liquid media of varying glucose concentrations, which were incubated at different temperatures. The cultures were sampled aseptically on successive days and growth was measured on the 'Spekker' absorptiometer. The experiment was carried out on the basal medium alone, and with the addition of 8,24 and $38 \%(w / w)$ glucose at temperatures of $17,25,30,37$ and $40^{\circ}$. Turbidity readings were taken until no further increase was recorded. The results are shown graphically in Figs. 1-4. These figures show that the presence of glucose in the medium, even in as low a concentration as $8 \%$, gives the yeast complete protection against temperatures otherwise lethal to it; without glucose it can grow slightly at $37^{\circ}$ and not at all at $40^{\circ}$, while with $8 \%$ glucose suboptimum or optimum growth can take place at the higher temperature. The time taken for the yeast to die when stored at $40^{\circ}$ in basal medium alone was determined, in order to discover whether this temperature merely inhibited or actually killed the organism in the absence of sugars. A vigorous 3-day old culture in malt broth was stored at $40^{\circ}$, and subcultured at intervals on to malt agar incubated at $30^{\circ}$. The yeast was found to be alive, but with greatly impaired viability, after $80 \mathrm{hr}$., and dead after $96 \mathrm{hr}$. These results may be compared with the effect of incubation at $37^{\circ}$ on $S$. rouxii growing in malt extract, where the still more concentrated medium allows growth for 4 weeks, but the yeast succumbs eventually (English, 1953). 


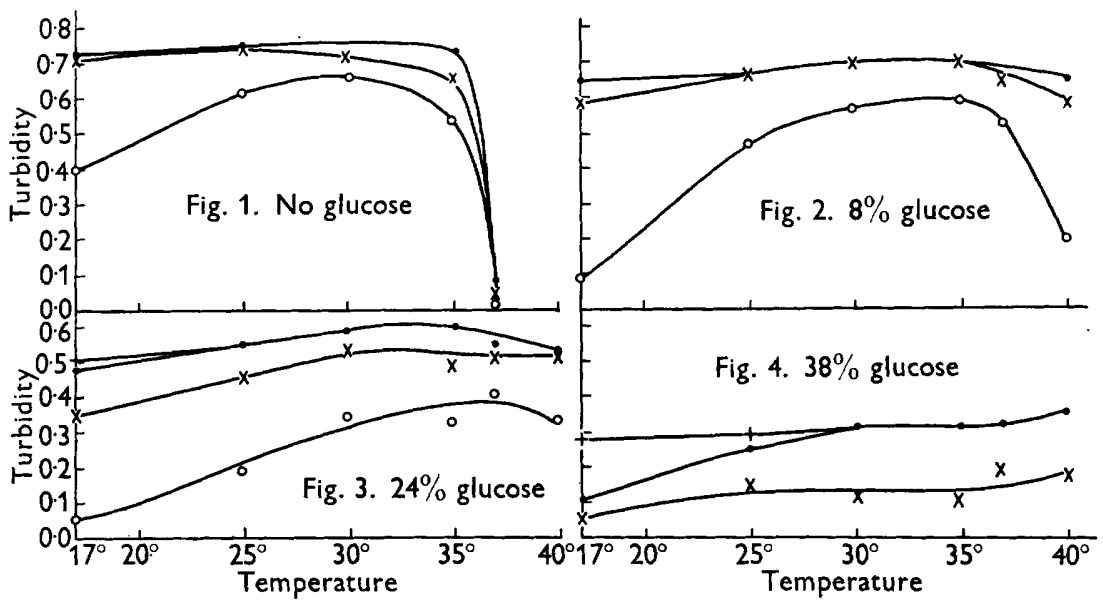

Figs. 1-4. The effect of temperature on $S$. rouxii grown in glucose solutions of different concentrations. Fig. 1. Basal broth without additional glucose. Fig. 2. Basal broth with $8 \%$ glucose. Fig. 3. Basal broth with $24 \%$ glucose. Fig. 4 . Basal broth with $38 \%$ glucose. $O=$ second day of incubation; $x=$ fourth day; $=$ seventh day; $+=$ ninth day.

\section{Thermal death-points}

These were determined for vegetative cells and spores in distilled water and in $70 \%(\mathrm{w} / \mathrm{v})$ maltose solution, as any substance more viscous could not be handled in capillary tubes. Vegetative cells were obtained from $48 \mathrm{hr}$. cultures on basal medium, scraped off and suspended in the test liquid: sporing cultures were taken from similar slopes 14 days old in which the presence of a large percentage of spores was confirmed microscopically. The results after 5, 10 and $15 \mathrm{~min}$. exposure are shown in Table 1.

Thermal death-points for honey and maple syrup strains of Z. japonicus have been determined to the nearest $5^{\circ}$ by Fabian \& Quinet (1928), and

Table 1. Thermal death-points of vegetative cells and spores of Saccharomyces rouxii

\begin{tabular}{|c|c|c|c|c|c|c|c|c|}
\hline \multirow{3}{*}{$\begin{array}{l}\text { Time } \\
\text { (min.) }\end{array}$} & \multicolumn{8}{|c|}{ Distilled water } \\
\hline & \multicolumn{4}{|c|}{ Vegetative cells } & \multicolumn{4}{|c|}{ Spores } \\
\hline & $46^{\circ}$ & $47^{\circ}$ & $48^{\circ}$ & $49^{\circ}$ & $\mathbf{5 5}^{\circ}$ & $56^{\circ}$ & $57^{\circ}$ & $58^{\circ}$ \\
\hline 5 & ++ & ++ & ++ & - & ++ & ++ & + & - \\
\hline 10 & ++ & + & + & - & ++ & + & - & - \\
\hline \multirow[t]{3}{*}{15} & + & - & - & - & ++ & - & - & - \\
\hline & \multicolumn{8}{|c|}{$70 \%$ maltose } \\
\hline & \multicolumn{4}{|c|}{ Vegetative cells } & \multicolumn{4}{|c|}{ Spores } \\
\hline (min.) & $48^{\circ}$ & $49^{\circ}$ & $50^{\circ}$ & $51^{\circ}$ & $58^{\circ}$ & $59^{\circ}$ & $60^{\circ}$ & $61^{\circ}$ \\
\hline $\mathbf{5}$ & ++ & ++ & + & - & ++ & ++ & + & - \\
\hline 10 & ++ & - & - & - & ++ & + & - & - \\
\hline 15 & ++ & - & - & - & + & - & - & - \\
\hline
\end{tabular}

$++=$ normal growth, $+=$ poor growth, $-=$ no growth. 
Fabian \& Hall (1933), and to the nearest $1^{\circ}$ for $S$. rouxii by Boutroux (1884), who, however, did not state whether spores or vegetative cells were used.

Though these investigators obtained their thermal death-points by different methods, so that absolute comparison of their results is impossible, all agree that there is an approximate difference of $10^{\circ}$ or more between the temperatures required to kill vegetative cells and spores. This contrasts with most of the results of Lund (1951) who found differences of 2-4 ${ }^{\circ}$ between spores and vegetative cells of most of his strains of $S$. ellipsoideus, $S$.turbidus and $S$. odessa. Only in one strain of $S$. odessa was there a difference of $12^{\circ}$.

\section{Effect of $\mathrm{pH}$ on growth}

This was studied in the basal medium with three levels of glucose, 4, 23 and $46 \%(\mathrm{w} / \mathrm{w})$. A range of $\mathrm{pH}$ values in each medium was obtained as has been described, and the growth of the yeast and acidity of the medium were determined on samples withdrawn aseptically at intervals throughout the experiment. The results obtained are shown in Figs. 5-10.

In all media, one further turbidity reading was made than is indicated by the last point on the appropriate graph. In 4 and $23 \%$ glucose (Figs. 5, 7) these readings were below those made on the preceding sample. Jordan \& Jacobs (1948) noticed a similar effect when the food content of the medium in which they were growing Escherichia coli reached starvation level. In $46 \%$ glucose (Fig. 9), on the other hand, they remained approximately the same or rose very slightly, indicating that growth had not quite ceased. It will be noticed that in the two less concentrated media, total growth was apparently submaximal at those $\mathrm{pH}$ values that allowed of the fastest growth rate (Figs. 5, 7). Although analogous observations have been made by others, in this case it seems that the result can be accounted for by the conditions under which the experiment was carried out. For the only times at which it was possible to take turbidity readings were those actually shown on the curves. These were adequate for the slow-growing cultures, but where conditions were very favourable and growth was rapid, the interval between two readings at the end of the growth period was sufficient to allow turbidity to reach its peak and then fall off, so that a true maximum was never recorded.

The figures show that the malt extract isolate of $S$. rouxii can tolerate an extremely wide $\mathrm{pH}$ range, from $2 \cdot 0$ to $8 \cdot 7$, and thus may differ considerably from Boutroux's original strain, of which he said 'Elle résiste mal l'acidité.' If, however, the medium in the alkaline range could be buffered against acid produced by the metabolism of the yeast, it is doubtful whether these $\mathrm{pH}$ levels would be so well tolerated by the malt yeast. For an examination of the curve for $\mathrm{pH} 8.7$ in Fig. 8 shows that the organism only grows at a $\mathrm{pH}$ above 8 for a comparatively short time, during which the growth rate as shown by the corresponding curve in Fig. 7 is slow. It is only when the yeast, by its own metabolism, has acidified the medium, that the growth rate increases. The relative humidity of a $46 \%$ glucose solution being about $87 \%$, this result may be compared with that obtained by Scarr (1951) for her 
osmophilic yeast strain 21, which failed to grow in $54 \%(w / w)$ sucrose solution (relative humidity over $90 \%$ ) at $\mathrm{pH} \mathbf{7 \cdot 8 .}$

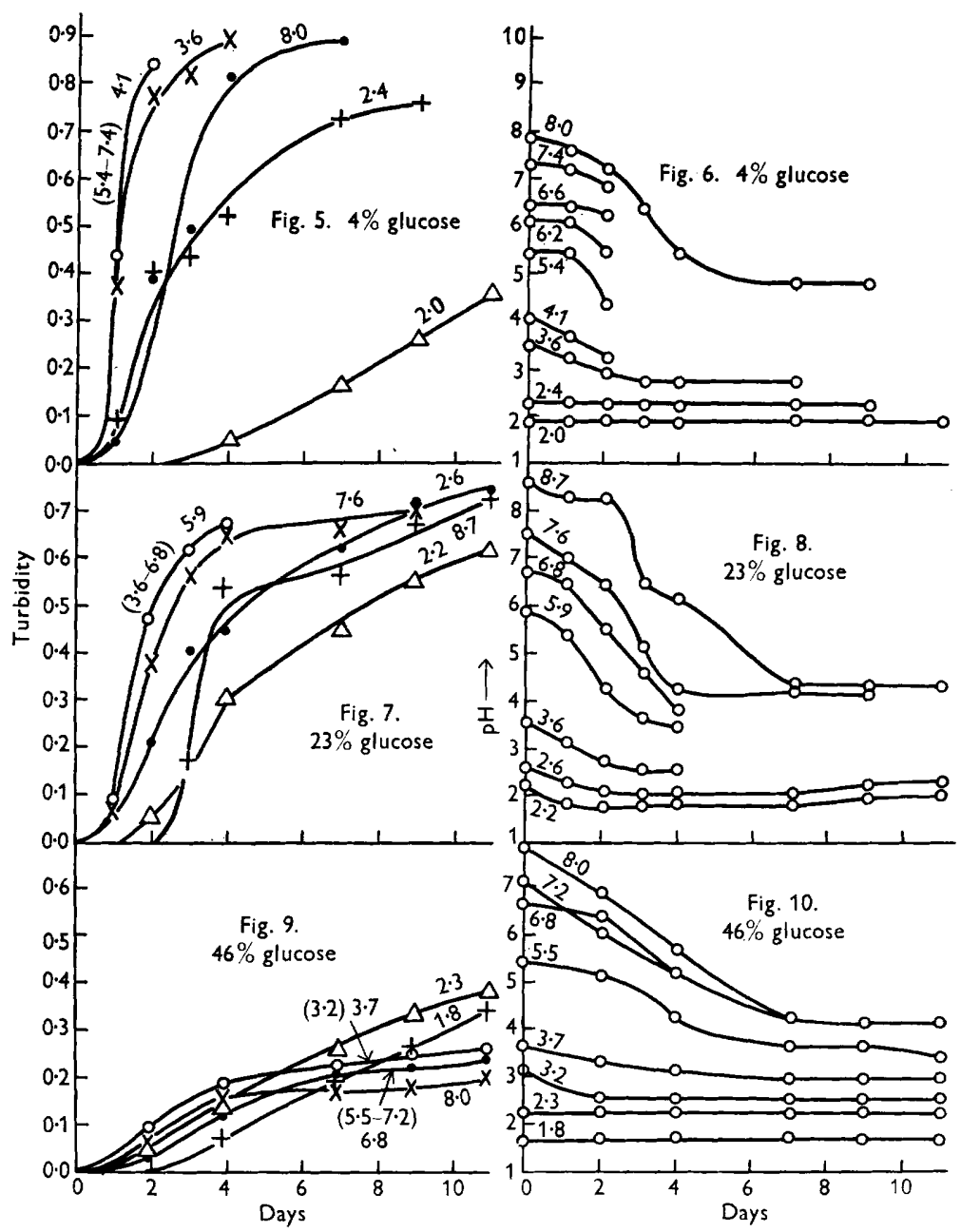

Figs. 5-10. The effect of the $\mathrm{pH}$ of the medium on $S$. rouxii grown in glucose solutions of different concentrations. Figs. 5, 7 and 9. Growth of the yeast in media containing 4,23 and $46 \%$ glucose respectively. Figs. 6, 8 and 10 . Change in $\mathrm{pH}$ of media containing 4, 23 and $46 \%$ glucose respectively, due to the growth of $S$. rouxii. The initial $\mathrm{pH}$ of the medium is marked on each curve. Figures in brackets indicate that media of these initial $\mathrm{pH}$ values gave results almost identical to the curve over which the figures appear.

\section{Nutrition}

A little preliminary work has been carried out on the vitamin nutrition and nitrogen requirements of $S$. rouxii, of which a short report follows. All glassware for these experiments was cleaned in chromic acid, and culture tubes were covered with metal caps instead of cotton-wool plugs. The basal defined medium contained $4 \%$ glucose, $0.2 \% \mathrm{KH}_{2} \mathrm{PO}_{4}, 0 \cdot 1 \% \mathrm{MgSO}_{4} .5 \mathrm{H}_{2} \mathrm{O}, 0.025 \%$ 
$\mathrm{CaCl}_{2}$, and $1 \mathrm{ml}$. lactic acid per $100 \mathrm{ml}$. medium, and was adjusted to $\mathrm{pH} 5 \cdot 0$ with $\mathrm{KOH}$.

Vitamins. $\mathbf{0} \cdot 4 \%\left(\mathrm{NH}_{4}\right)_{2} \mathrm{HPO}_{4}$ was added to the basal defined medium, and the following vitamins were tested alone and in combination (per $100 \mathrm{ml}$. medium): biotin, 0.2 $\mu \mathrm{g}$., inositol $1000 \mu \mathrm{g}$., calcium D-pantothenate $100 \mu \mathrm{g}$.

The results appear in Table 2 and show that biotin, which is known to occur in malt extract, is the only one of these vitamins essential for growth.

Table 2. Vitamins necessary for the growth of Saccharomyces rouxii

\begin{tabular}{lclc}
\multicolumn{1}{r}{ Vitamin } & Growth & \multicolumn{1}{c}{ Vitamin } & Growth \\
None & - & Biotin + inositol & ++ \\
Biotin & ++ & Biotin + Ca pantothenate & ++ \\
Inositol & - & Inositol + Ca pantothenate & - \\
Ca pantothenate & - & Complete & ++
\end{tabular}

$++=$ growth and fermentation. $-=$ no growth.

Table 3. Growth of Saccharomyces rouxii on various nitrogen-containing compounds

\begin{tabular}{|c|c|c|c|}
\hline Heavy & Moderate & Poor & None \\
\hline $\begin{array}{l}\text { Casein } \\
\text { hydrolysate }\end{array}$ & $\begin{array}{l}\text { Adenine } \\
\text { Alanine } \\
\text { Asparagine } \\
\text { Glutamic acid } \\
\text { Glutamine } \\
\text { Guanine } \\
\text { Tryptophan } \\
\text { Uracil } \\
\text { Xanthine }\end{array}$ & $\begin{array}{l}\text { Arginine } \\
\text { Valine }\end{array}$ & $\begin{array}{l}\text { Choline } \\
\text { Cystine } \\
\text { Hydroxyproline } \\
\text { Isoleucine }\end{array}$ \\
\hline
\end{tabular}

Lochhead \& Landerkin (1942), in their study of the vitamin requirements of osmophilic yeasts, divided their organisms into three groups according to whether pantothenic acid was unnecessary, stimulatory or essential for their growth. In this scheme, my isolate of $\boldsymbol{S}$. rouxii falls into the first group, in that neither pantothenic acid nor inositol is essential or stimulatory. Thus the malt yeast differs in its vitamin requirements from the strain of $\boldsymbol{Z}$. japonicus isolated from normal honey, on which these authors worked, as pantothenic acid was essential to their organism.

Nitrogen. For these experiments $0 \cdot 2 \mu \mathrm{g}$. biotin $/ 100 \mathrm{ml}$. was added to the basal defined medium, and a number of amino acids were tested as possible sources of nitrogen, at a concentration of $1 \mathrm{mg}$. $/ 100 \mathrm{ml}$. Negative and positive controls were included, the latter containing $0.4 \%\left(\mathrm{NH}_{4}\right)_{2} \mathrm{HPO}_{4}$. The results are shown in Table 3.

\section{DISCUSSION}

These experiments make it clear that $S$. rouxii is a facultative rather than an obligate osmophile, and that it is an adaptable organism, tolerant of a wide range of environmental conditions, its power of survival at temperatures over $35^{\circ}$ being greatly enhanced by the addition of a small quantity of sugar to the medium. 
Of those who have worked previously on yeasts identified as $\boldsymbol{Z}$. japonicus, only Fabian \& Quinet mention the lower limits of sugar concentration at which the yeast can grow, and then only indirectly, in that Z. japonicus is included in the list of species isolated from honey, and they state that they were unable to obtain any osmophilic yeasts from honey in media containing $10 \%$ or less of sugar. If the latter observation applies to any sample containing $\boldsymbol{Z}$. japonicus, their yeast behaved in a very different manner from the malt organism, but from the data it is impossible to be sure of this. It is known that other osmophilic yeasts can grow in very dilute media; for instance, Ingram (1949) was able to grow an unnamed yeast from concentrated orange juice, on potato glucose agar.

The temperature relationships of $S$. rouxii differ from those reported for other osmophilic yeasts, where these have been investigated, in the striking effect of comparatively low concentrations of sugars in protecting the organism against otherwise lethal temperatures. Krumbholz (1931 $a$ ) found that $30 \%$ $(\mathbf{w} / \mathrm{v})$ of sugar was insufficient to allow growth of four strains of $\boldsymbol{Z}$. polymorphus at $40^{\circ}$, but that good growth was obtained with $40 \%$ sugar. In a fifth strain, feeble growth occurred at $40^{\circ}$ in $30 \%(\mathrm{w} / \mathrm{v})$ sugar, but none in a $20 \%$ syrup. $S$. rouxii, however, can grow at this temperature in the presence of as little as $10 \%(\mathrm{w} / \mathrm{v})(8 \%, \mathrm{w} / \mathrm{w})$ glucose, when without it is killed after $96 \mathrm{hr}$. exposure.

It is difficult to imagine that so small a quantity of sugar can bring about such an effect only by the slight increase in osmotic strength of the solution, yet it must apparently cause some radical change in the metabolism of the cells or in their equilibrium with the environment.

I should like to thank the following for their assistance: Mr J. T. Gunner and Miss Constance Rainbow of this Department for invaluable technical help: Dr C. J. Hickman and Dr C. Rainbow of the University of Birmingham for reading and criticizing the manuscript: Dr S. W. F. Underhill of this Department for his interest in and encouragement of the work; and the Directors of 'The British Drug Houses Ltd. for permission to publish the results of the investigation.

\section{REFERENCES}

Boutroux, M. L. (1884). Sur la conservation des ferments alcooliques dans la nature. Ann. Sci. nat. (Bot.), Ser 6, 17, 144.

English, M. P. (1953). The fermentation of malt extract by an osmophilic yeast. J. gen. Microbiol. 9, 15.

Fabian, F. W. \& Hall, H. H. (1933). Yeasts found in fermented maple syrup. $Z$ Zbl. Bakt. (2. Abt.), 89, 31.

Fabian, F. W. \& Quinet, R. I. (1928). A study on the cause of honey fermentation. Tech. Bull. Mich. agric. Exp. Sta. 48, no. 92.

Ingram, M. (1949). Fermentation in concentrated orange juice. Food Manuf. 24, $7 \%$.

Ingram, M. (1950). Osmophilic yeasts from concentrated orange juice. J. gen. Microbiol. 4, ix.

JACKSON, R. F. \& Silsbee, C. G. (1922). The solubility of dextrose in water. Sci. Pap. U.S. Bur. Stand. 17, 715.

Jordan, R. C. \& JacoBs, S. E. (1948). The effect of $\mathrm{pH}$ at different temperatures on the growth of Bacterium coli with a constant food supply. J. gen. Microbiol. $2,15$. 
Kroemer, K. \& Krumbhol.z, G. (1931). Untersuchungen über osmophile Sprosspilze I. Arch. Mikrobiol. 2, 352.

Kroemer, K. \& Krumbrolz, G. (1932). Untersuchungen über osmophile Sprosspilze. V. Arch. Mikrobiol. 3, 384.

Krumbrolz, G. (1931a). Untersuchungen über osmophile Sprosspilze. II. Arch. Mikrobiol. 2, 411.

Krumbiolz, G. (1931b). Untersuchungen über osmophile Sprosspilze. III. Arch. Mikrobiol. 2, 601.

Lochhead, A. G. \& Landerkin, G. B. (1942). Nutrilite requirements of osmophilic yeasts. J. Bact. 44, 343.

Lund, A. (1951). Some beer spoilage yeasts and their heat-resistance. J. Inst. Brew. 57, 36.

Nickerson, W. J. \& Carrold, W. R. (1945). On the metabolism of Zygosaccharomyces. Arch. Biochem. 7, 257.

Nickerson, W. J. \& Thimann, K. V. (1943). The chemical control of conjugation in Zygosaccharomyces. II. Amer. J. Bot. 30, 94.

SaIto, K. (1907). Mikrobiologische Studien über die Soyabereitung. Zbl. Bakt. (2. $A b t.), 17,20$.

ScARr, M. P. (1951). Osmophilic yeasts in raw beet and cane sugars and intermediate sugar-refining products. J. gen. Microbiol. 5, 704. 